\title{
VeneZuela 2010-2011: PolariZación Y RADICALIZACión DEL PROYECTO SOCIALISTA*
}

\author{
Venezuela 2010-2011: Polarization and Radicalization \\ of the socialist project
}

\section{RICKARD LALANDER}

Universidad de Estocolmo

\begin{abstract}
RESUMEN
En Venezuela el bienio de 2010 y 2011 se caracterizó por una polarización política y social y la radicalización continua del gobierno socialista de Hugo Chávez Frías, con la ejecución de nuevas leyes, oficialmente para expandir y profundizar la democracia participativa y radical. Paralelamente, también se manifestó el retorno de la oposición política a partir de las elecciones parlamentarias de 2010. En el 2011, la crisis interna ya existente dentro del chavismo se acentuó con la enfermedad del presidente Chávez y los aspectos de incertidumbre en cuanto al liderazgo de un movimiento político que hasta la fecha se ha caracterizado por un alto grado de personalismo y poder concentrado en el Presidente. En el campo social, el gobierno ha mantenido sus políticas progresistas/asistencialistas de diferentes Misiones sociales del Estado, especialmente a partir del 2011 para confrontar la escasez habitacional. En 2011 igualmente se puede observar el inicio de la precampaña electoral para las presidenciales del 2012. En el presente estudio se ofrece un resumen político de Venezuela en 2010 y 2011 y habrá un enfoque analítico particular en las elecciones parlamentarias de 2010, así como en las tensiones entre dos modelos democráticos: uno liberal representativo y otro más radical y participativo. De este último modelo, habrá un énfasis especial en la evolución de los consejos comunales y sus implicaciones para la democracia.
\end{abstract}

Palabras clave: Democracia, elecciones, Hugo Chávez, polarización, socialismo del siglo XXI, Venezuela.

\begin{abstract}
The years of 2010 and 2011 were characterized by political and social polarization and similarly by a radicalization of the socialist government of Hugo Chávez Frias, with the establishment of new laws to expand the model of radical participatory democracy. The period however also witnessed the return of the opposition to the National Assembly in 2010. In 2011, the already existing crisis within the chavismo was hit by the health problems of the President, which added to uncertainty regarding the leadership of a movement that hitherto has been characterized by a high degree of personalism and power concentration in Chávez. In the social field, the government has maintained its progressive (and/or paternalist) policies of different State Social Missions (Misiones), since 2011 mainly to confront housing shortages. Already in 2011, the beginning of a pre-campaign before the presidential elections of 2012 can be observed. This
\end{abstract}

* $\quad$ El autor quiere agradecer al Dr. Juan Velásquez, el Dr. Weine Karlsson y otros colegas que contribuyeron con comentarios sobre el manuscrito del estudio en el seminario interno de investigación del Instituto de Estudios Latinoamericanos, Universidad de Estocolmo, 14 de febrero, 2012. Asimismo, un agradecimiento a mis estudiantes en el curso Contemporary Debate on Venezuelan Politics and Society, programa de maestría en Estudios Latinoamericanos, Universidad de Helsinki, Finlandia, diciembre de 2011. 
study provides a political summary of Venezuela in 2010 and 2011, and there will be special analytical attention paid to the parliamentary elections of 2010, and-particularly-the tensions between two different democratic schemes: a liberal representative model and a more radical and participatory type of democracy. As for the second type there will be special attention to the Community Councils and their implications for Venezuelan democracy.

Key words: Democracy, elections, Hugo Chávez, polarization, 21st century Socialism, Venezuela.

\section{INTRODUCCIÓN}

Los años 2010 y 2011 quedaron marcados en la historia venezolana por diferentes razones políticas. En las elecciones parlamentarias del 2010, la oposición volvió a la Asamblea Nacional y el oficialismo perdió el control que tenía del cuerpo legislativo. Sin embargo, el partido oficialista -el PSUV (Partido Socialista Unido de Venezuela)- se destacó como agrupación política más fuerte en la nueva Asamblea Nacional. La noticia venezolana más impactante del 2011, con sus evidentes dimensiones políticas, trató del estado de salud y el cáncer del presidente Hugo Rafael Chávez Frías, y de esta manera se puso en el tapete una vez más cuán dependiente el chavismo es de su máximo líder. A continuación el debate sobre la era chavista tomará en consideración el aspecto de antes o después de la enfermedad del primer mandatario.

Económicamente, la recesión de 2009 se extendió al 2010, mientras que el año siguiente presentó una recuperación y crecimiento positivo. En lo social, las estrategias para reducir la pobreza y la desigualdad social han sido exitosas, así como los avances para alcanzar las metas del milenio en concordancia con la ONU (Organización de las Naciones Unidas) y en gran medida a través de la labor de las diferentes misiones sociales del Estado. El viejo problema de escasez habitacional empeoró aún más con las fuertes lluvias y las inundaciones de diciembre del 2011. En abril de 2011 se lanzó la Gran Misión Vivienda, y casi se alcanzó la meta de construcción de viviendas para el año. En total se establecieron cuatro nuevas Misiones sociales en 2011: además de la Mision Vivienda, se lanzó la Misión Agro Venezuela, y al final del año las misiones Hijos de Venezuela y En Amor Mayor respectivamente. Es importante aclarar que el presidente Chávez se aprovechó de la crisis social que emergió luego de las inundaciones y se aceleró la autorización de poderes especiales legislativos del Presidente durante cierto tiempo definido -una Ley Habilitante-, proceso otorgado por la saliente Asamblea Nacional, lo que se presentará con más detalle a continuación.

Valga mencionar, asimismo, que el fallecimiento en Estados Unidos, en diciembre de 2010, del ex presidente Carlos Andrés Pérez/CAP -una de las figuras políticas más emblemáticas y controvertidas de la historia democrática de Venezuela- causó un debate emocional sobre su entierro entre familiares, políticos y la amante de Pérez. CAP, que se encontraba en el exilio luego de procesos judiciales en su contra, y que quería morir y descansar pacíficamente en tierra venezolana, en alguna ocasión había expresado que no se permitiría regresar a una Venezuela gobernada por Hugo Chávez. ${ }^{1}$

$1 \quad$ El 4 de febrero de 1992, Hugo Chávez lideró el intento de golpe de Estado contra el Presidente Carlos Andrés Pérez, y desde aquel entonces Chávez y Pérez son enemigos políticos y personales hasta la muerte. No obstante, 
En cuanto a la estructura y el contenido del artículo, luego de la presente introducción habrá un resumen muy breve de las relaciones internacionales de Venezuela durante el período, seguido por una reflexión de la coyuntura social y económica. Luego se presenta una sección central del estudio sobre las elecciones parlamentarias del 2010 y el retorno de la oposición. A continuación se ofrece un sumario de la labor del Poder Legislativo, seguido por un análisis de las tensiones entre la democracia liberal representativa y un modelo democrático más radical y participativo, especialmente considerando la expansión del poder comunal y el caso de los consejos comunales. Antes de redondear con algunas conclusiones pertinentes se presenta una sección substancial sobre la posible crisis del chavismo, y luego una reflexión sobre la enfermedad del presidente Chávez y las movilizaciones relacionadas a la precampaña electoral ante los comicios presidenciales del 2012.

\section{RELACIONES INTERNACIONALES}

En cuanto a las relaciones comerciales y diplomáticas entre Venezuela y la administración estadounidense de Barack Obama no hubo controversias graves durante el período y la exportación venezolana de petróleo a EE.UU. sigue sin cambios dramáticos. En comparación con la situación durante la administración de George W. Bush, se suavizó el tono provocativo antiestadounidense de Chávez. No obstante, sí hay preocupación en Washington por las relaciones que se han profundizado entre Venezuela con Rusia, China, y, en particular, con Irán. En una entrevista a Barack Obama al final de 2011 el Presidente estadounidense expresó su inquietud con respecto a los vínculos venezolanos con Irán (El Universal, 18 de diciembre, 2011). ${ }^{2}$

En las relaciones diplomáticas con Colombia hubo mejoras sustanciales con el cambio de Presidente en el país vecino. Una vez electo, el nuevo Presidente colombiano Juan Manuel Santos decidió priorizar la armonización de las relaciones con Venezuela que habían empeorado durante el mandato anterior de Álvaro Uribe. Colombia sigue siendo uno de los socios económicos más importantes de Venezuela, así como Brasil y otros países latinoamericanos. El período igualmente vio el nacimiento de una nueva organización de integración regional latinoamericana, la Comunidad de Estados Latinoamericanos y Caribeños/CELAC, la cual fue creada en México en febrero del 2010 y tuvo su asamblea de constitución definitiva en Caracas en diciembre de 2011. Es decir, la CELAC se presenta como otro organismo continental, principalmente como una opción a la OEA (Organización de los Estados Americanos) y paralelamente al Mercosur (Mercado Común del Sur), el ALBA (Alternativa Bolivariana para los Pueblos de Nuestra América) y la UNASUR (Unión de Naciones Suramericanas).

el Presidente Chávez no presentó ningún obstáculo para que se organizara el entierro en Venezuela y diez meses después de su muerte se realizó la despedida de CAP en Caracas.

2 http://www.eluniversal.com/nacional-y-politica/111219/vinculos-del-gobierno-venezolano-con-iran-ycuba-no-benefician-a-su-ge 


\section{COYUNTURA SOCIAL Y ECONÓMICA}

Luego de la recesión económica que marcó los años 2009 y 2010, hubo una recuperación parcial en 2011 con un crecimiento económico de 4\%. Según la OPEP (Organización de Países Exportadores de Petróleo), la producción petrolera venezolana aumento en 2011 con el 4,2\% en promedio, considerando los primeros tres trimestres del 2011 en comparación al mismo período de 2010. La inflación sigue siendo alta, y cerró en 27,9\% en 2011, lo que significa un aumento de $0,4 \%$ en comparación con el año anterior. El desempleo se estableció en 2010 y hubo una reducción durante la segunda mitad de 2011 (8,3\%, en el tercer semestre de 2011). Hubo un aumento de $27,2 \%$ de los salarios en el sector privado en el 2011 y los salarios públicos subieron un 58,6\%. Los aumentos drásticos en parte se deben al alza del salario mínimo (CEPAL, 2011).

\section{Algunos indicadores socioeconómicos}

Tasas de variación anual (CEPAL, 2011) ${ }^{3}$

\begin{tabular}{lccc}
\hline & 2009 & 2010 & 2011 \\
\hline Producto Interno Bruto/PIB & $-3,2$ & $-1,5$ & 4,2 \\
PIB por habitante & $-4,8$ & $-3,0$ & 2,6 \\
Precios al consumidor & 26,9 & 27,4 & 28,9 \\
Salario medio real & $-6,6$ & $-5,2$ & 3,0 \\
\hline
\end{tabular}

En cuanto a la moneda oficial, el 1 de enero de 2011 se unificó el tipo de cambio en la paridad de 4,3 bolívares fuertes (BsF.) por el dólar, dejando así la paridad cambiaria anterior de 2,6 BsF. Valga aclarar que existen cursos paralelos extraoficiales de la moneda. En el mercado negro especuladores compran dólares por entre 8 y 12 bolívares fuertes según observaciones en el 2011.

En cuanto a la estrategia para la reducción de la pobreza y la desigualdad social, a largo y corto plazo se presentan cifras positivas. Entre 1990 y 2010 la pobreza disminuyó en más del 50\% (CEPAL, 2011) y según la ONU se confirma que la pobreza por hogares se redujo del 43,9\% en 1998 a un 26,7\% en 2011. Durante el mismo período, la pobreza extrema disminuyó de $17,1 \%$ al 7\%. ${ }^{4}$ Adicionalmente, como se mencionó, Venezuela está alcanzando las Metas del Milenio de la ONU, en gran parte a través de las Misiones sociales del Estado. Con respecto al avance de la Gran Misión Vivienda, durante 2011 lograron construir 146.714 unidades habitacionales, así que casi se alcanzó la meta prevista de 153.000 viviendas (RNV, 20 de enero, 2012). ${ }^{5}$

http://www.eclac.cl/publicaciones/xml/1/45581/2011-881_BPE_Venezuela_29dic11.pdf Las cifras para 2011 son estimaciones preliminares.

4 http://venezuela-us.org/es/2012/02/06/venezuela-cumplira-con-anticipacion-las-metas-del-milenio-de-la-onu/print http:/ / www.rnv.gob.ve/noticias/index.php?act=ST\&f=2\&t=174822 
No obstante, hay datos más negativos que se han reflejado en Venezuela, los sistemas hidroeléctricos han sufrido algunos colapsos. Asimismo, temporalmente ha habido escasez de alimentos, medicamentos y otros rubros durante el período. Hay ciertos retrocesos económicos en cuanto al consumo de rubros importados y fallas parciales en la provisión de productos agrícolas básicos. Según el Banco Central de Venezuela, en 2011 se registró el mayor aumento en importaciones desde 2007. El ministro de Agricultura y Tierras, Juan Carlos Loyo, admite que hubo una caída en la producción, por ejemplo, de maíz, soya, plátano, palma aceitera y caña de azúcar (El Universal, 18 de febrero, 2012).

El gobierno ha seguido con sus políticas de nacionalizaciones y expropiaciones de empresas, por ejemplo el caso de la cadena de supermercados Éxito (que pertenecía al grupo francés Casino) en el inicio de 2010. A mediados de 2010 se ordenó la nacionalización de once taladros petroleros de la compañía estadounidense Helmerich \& Payne (El Universal, 26 de octubre, 2010). ${ }^{6}$

La estadística de protestas sociales igualmente muestra un incremento. Como en la gran parte de América Latina, las inquietudes sociales venezolanas más fuertes se concentran en la inseguridad, la violencia y la criminalidad. En Venezuela se destacan las cifras oscuras de la tasa de homicidios. Según la ONG académica OVV/Observatorio Venezolano de Violencia, hubo 17.600 asesinatos en 2010 y en 2011 aumentó hasta 19.336, lo que resulta en una tasa nacional de 67 homicidios por cada 100.000 habitantes.

En junio del 2011 el país vivió su crisis carcelaria más grave hasta la fecha. Los problemas penitenciarios son de larga data, y se trata tanto de los derechos humanos de los presos, la corrupción de guardias y otros funcionarios del Estado y el creciente poder de bandas criminales que controlan el tráfico de armas, drogas, celulares, etc., incluso desde las cárceles. La crisis de 2011 se inició en la cárcel de El Rodeo 1 y 2 como una guerra armada entre dos bandas criminales. En esta situación, ni los militares, los guardias y los policías podían entrar por varias semanas y se produjo un saldo de por lo menos 25 personas asesinadas y un gran número gravemente heridas. Finalmente intervinieron 5.000 funcionarios y hubo un tipo de tregua entre las bandas que no querían más muertos. Para la historiadora y politóloga Margarita López Maya (2011: 10), este episodio violento de El Rodeo "mostró la cara más oscura de un gobierno ineficiente, penetrado en algunas de sus instancias por la corrupción y el narcotráfico". Al mismo tiempo, López Maya por cierto reconoce que los problemas carcelarios no comenzaron con el chavismo, sino que llevan una larga historia. Es importante destacar también que hubo una politización de la crisis carcelaria y la situación en El Rodeo se transformó en plataforma de la oposición para denunciar al gobierno como culpable de la situación. Asimismo hubo ejemplos de manipulación mediática sobre la situación carcelaria. Meses después de haberse calmado la situación, luego de un juicio penal, el canal televisivo privado opositor Globovisión fue sentenciado a pagar una multa

6 Para una cronología de nacionalizaciones y expropiaciones, véase: http:/ / www.eluniversal.com/2010/10/26/ expro_esp_cronologia-de-nacion_26A4655497.shtml 
de 2,16 millones de dólares (BsF 9,3 millones) por manipulación informativa y por haber causado temor entre los ciudadanos a través de sus reportajes de el Rodeo (Venezuelanalysis.com, 19 de octubre, 2011). ${ }^{7}$

\section{LAS ELECCIONES PARLAMENTARIAS DE 2010: EL RETORNO DE LA OPOSICIÓN}

Ahora bien, como se mencionó en la introducción, en las elecciones parlamentarias del 26 de septiembre de 2010 la oposición que se había fortalecido y unificado a partir del 2006 logró medirse con el oficialismo y ocupar un espacio importante en el cuerpo legislativo. En las elecciones parlamentarias de 2005, la alianza chavista se había encargado del 100\% de los puestos en la Asamblea Nacional, hasta alto grado el fruto de la decisión de la mayoría de la oposición de boicotear las elecciones. ${ }^{8}$

La distribución de los escaños según el resultado final significó que el oficialismo tuvo 98 diputados en la nueva Asamblea Nacional, de los cuales 94 fueron elegidos en representación del Partido Socialista Unido de Venezuela/PSUV, tres por el Partido Comunista de Venezuela/PCV, y un diputado del movimiento indígena CONIVE (Consejo Nacional Indio de Venezuela). La oposición representada por la alianza de la Mesa de Unidad Democrática /MUD obtuvo 65 asientos parlamentarios. Las agrupaciones partidistas más fuertes de la oposición son Un Nuevo Tiempo/UNT y Acción Democrática/AD. Mientras que los socialdemócratas de Acción Democrática -junto con el partido socialcristiano COPEI- ${ }^{9}$ representan el tradicionalismo político de la Venezuela pre-Chávez; el UNT se formó a nivel regional en el estado Zulia en 1999, inicialmente alrededor de unos dirigentes anteriormente adecos (militantes de AD). A partir del proceso electoral de 2006, UNT se ha expandido y militantes y dirigentes de otros grupos políticos opositores se han unido al partido.

Una novedad en este proceso electoral fue la participación de un nuevo bloque político entre el oficialismo y la oposición. La idea era capitalizar los votos de los indecisos, los ciudadanos que no se identificaban ni con el oficialismo ni con la oposición, popularmente conocidos como los ni-nís. El actor político principal de este tipo de oposición crítica constructiva en este proceso electoral fue el partido Patria Para Todos/PPT, que había sido uno de los aliados centrales del chavismo a partir de 1997. Ya antes de las elecciones parlamentarias el PPT había salido de la coalición oficialista. El partido al final logró 354.677 votos y dos asientos parlamentarios, lo que probablemente fue mucho menos que las expectativas. Vale aclarar que no sólo el PPT es un ex aliado importante del chavismo. El movimiento PODEMOS (Por la Democracia Social) de igual forma anteriormente fue parte del chavismo, e históricamente -en los años 90- también la Causa R (Causa Radical) estuvo vinculada al movimiento de Chávez.

http://venezuelanalysis.com/print/6569.

Es decir, con el enfoque en estas elecciones de 2005, Venezuela casi podría clasificarse como un sistema monopartidista a nivel parlamentario. La alianza chavista logró el control absoluto de la Asamblea, y el Movimiento Quinta República/MVR, el partido político oficialista principal antes de la formación del PSUV, estuvo representado con 114 diputados de los 167 curules.

9 Comité de Organización Política Electoral Independiente. 


\section{Distribución de representación política partidista en la Nueva Asamblea Nacional:}

Elecciones parlamentarias en Venezuela, 2010 (CNE, 2010)

\begin{tabular}{lcc}
\hline Partido/movimiento político & Oficialismo & Oposición (y el PPT) \\
\hline PSUV & 94 & \\
PCV & 3 & \\
CONIVE & 1 & \\
UNT & & 15 \\
AD & 14 \\
COPEI & 7 \\
Primero Justicia & 6 \\
Podemos & 4 \\
Causa R & 3 \\
Proyecto Venezuela & & 3 \\
Alianza Bravo Pueblo/ABP & & 1 \\
Cuentas Claras & & 1 \\
DALE & & 1 \\
Convergencia & 1 \\
Gente Emergente & 1 \\
Diputados independientes & & 7 \\
PPT & 98 & 2 \\
Total: & & 67 \\
\hline
\end{tabular}

Debe clarificarse un hecho importante en estas elecciones. En la tabla de arriba se presenta el oficialismo como fuerza de mayoría absoluta (59,4\% de los asientos, lo que se compara con $39 \%$ para la MUD y 1,2\% para el PPT). Sin embargo, en números exactos de votos obtenidos, el oficialismo no alcanzó el 50\% de los votos, sino el 48,2\% de los votos totales, mientras que la MUD sumando al PPT lograron 51,8\% de los votos. ${ }^{10}$ ¿Cómo se explicaría entonces que el oficialismo obtuvo el 59,4\% de los asientos, la MUD el 39,4\% y el PPT el 1,2\%? Primero, hay que constatar que Venezuela tiene un sistema electoral mixto. Para las elecciones parlamentarias el 30\%, o 52 curules, son electos a través de representación proporcional partidista al nivel de Estado. El restante 70\%, o 113 asientos, es electo directamente como representante de distritos electorales. De esta manera hay dos tipos de votos, primero por la lista partidista de candidatos y segundo la selección de candidato(s). Dependiendo del tamaño en población del distrito electoral, se elige entre uno a tres candidatos. 
El sistema electoral venezolano siempre ha beneficiado la representación rural, con el objetivo de ofrecer espacio legislativo y político también para las zonas más escasamente pobladas. En 2009 se modificó la Ley Orgánica de Procesos Electorales, y en consecuencia se disminuyó el modelo de $40 \%$ de representación proporcional que regía los procesos anteriores, a un $30 \%$. Si hubiera funcionado el sistema anterior, la oposición hubiera obtenido $45 \%$ de los asientos (74 curules), en vez de 39\%. Así que en todo caso no hubiera afectado la situación de la mayoría absoluta del oficialismo en el Parlamento (Wilpert, 2010). ${ }^{11}$

Una implicación importante del resultado de este proceso electoral es, sin embargo, que el oficialismo perdió su posición de mayoría cualificada para poder autorizar poderes especiales al Presidente para legislar por decreto mediante una Ley Habilitante. La mayoría cualificada es de 66,7\% de los asientos, es decir, el oficialismo hubiera necesitado 110 curules parlamentarios para poder seguir con esta práctica, lo que fue precisamente la meta oficial del chavismo durante la campaña electoral. Hasta la instalación de la nueva Asamblea Nacional, el chavismo podía legislar "más tranquilamente". El oficialismo indudablemente sospechaba que iba a perder su mayoría cualificada en el Parlamento y estaba preparado para arreglar otra Ley Habilitante, lo que oficialmente se justificó por la extrema situación de inundaciones y el gran número de ciudadanos damnificados al final de 2010. Como clarifica Margarita López Maya (2011: 6-7), Chávez pidió a la saliente Asamblea Nacional autoridad extraordinaria para legislar en nueve áreas temáticas, incluso en la política petrolera y económica. De esta manera la nueva Asamblea Nacional fue neutralizada, o por lo menos fue decisivamente debilitada.

Adicionalmente, se debe agregar que algunas elecciones subnacionales - de alcaldes y gobernadores- se realizaron el 5 de diciembre de 2010. En los estados Amazonas y Guárico se realizaron elecciones de gobernadores del estado. En el caso de Amazonas, el retraso del período electoral se debía a la prórroga de elecciones estadales en esta unidad político-territorial a partir del año 2000, así que el período del mandato regional culminó en 2010. Sin embargo, el Gobernador anterior Liborio Guarulla del partido PPT aseguró su reelección en este proceso con el 51,07\% de los votos. En el estado Guárico, el Gobernador Willian Lara del PSUV había fallecido en un accidente de tránsito en septiembre de 2010 y por ende tuvieron que realizar nuevos comicios para la Gobernación, en los cuales triunfó Luis Gallardo del PSUV con el 77,09\% de apoyo electoral. Asimismo, se efectuaron elecciones de alcaldes en once municipios. Candidatos del PSUV triunfaron en siete municipios, ${ }^{12}$ y la oposición en cuatro. ${ }^{13}$

\section{PODER LEGISLATIVO Y DECRETISMO PRESIDENCIAL}

Como ya fue mencionado, a partir de la instalación de la nueva Asamblea Nacional en 2010 la oposición ya está fuertemente presente en el Poder Legislativo. No obstante,

11 Para reflexiones críticas de este tema, véase también López Maya, 2011, y Súmate, 2010.

12 Los municipios de Achagas (estado Apure), Miranda (en Carabobo), Boconó (en Trujillo), Miranda (Trujillo), Manuel Monge (en Yaracuy), Nirgua (Yaracuy) y Miranda (en Zulia).

13 Los municipios de Carrizal (estado Miranda, por UNT), Arismendi (en Nueva Esparta, por Primero Justicia), Panamericano (en Táchira, por COPEI), y el municipio de Maracaibo (en Zulia, por UNT). 
la legislación presidencial por decreto mediante Ley Habilitante en algunos períodos -especialmente en el 2011- ha superado el proceso normal parlamentario de redactar leyes en Venezuela. El decretismo presidencial es una de las características del concepto de democracia delegativa, como diría Guillermo O’Donnell (1994).

Leyes sancionadas en 2010 (Datos tomados de la página web de la Asamblea Nacional)

- Ley del Artesano y Artesana Indígena.

- Ley para la Protección de la Fauna Doméstica Libre y en Cautiverio.

- Ley de Reforma Parcial de la Ley para la Defensa de las Personas en el Acceso a los Bienes y Servicios.

- Ley Especial de Supresión y Liquidación del Instituto Autónomo Fondo Unico Social (IAFUS).

- Ley Especial de Supresión y Liquidación del Instituto Autónomo Corporación para la Recuperación y Desarrollo del estado Vargas (CORPOVARGAS).

- Ley Orgánica del Consejo Federal de Gobierno.

- Ley de Reforma Parcial de la Ley que crea la Condecoración de la Orden José Félix Ribas.

- Ley Derogatoria de la Ley que crea el Fondo Intergubernamental para la Descentralización (FIDES).

- Ley de Creación de la Academia de Ciencias Agrícolas de Venezuela (ACAV).

- Ley de Reforma Parcial de la Ley del Banco Central de Venezuela.

- Ley de Reforma Parcial de la Ley contra los Ilícitos Cambiarios.

- Ley de Reforma Parcial del Decreto N 6.214, con Rango, Valor y Fuerza de Ley del Banco de Desarrollo Económico y Social de Venezuela (BANDES).

- Ley de Reforma Parcial de la Ley del Estatuto sobre el Régimen de Jubilaciones y Pensiones de los Funcionarios o Funcionarias, Empleados o Empleadas de la Administración Pública Nacional de los Estados y de los Municipios.

- Ley de Reforma Parcial del Decreto N 6.266 con Rango, Valor y Fuerza de Ley de Reforma Parcial de la Ley del Seguro Social.

- Ley Orgánica de la Jurisdicción Contencioso Administrativa.

- Ley Orgánica del Sistema Financiero Nacional.

- Ley Orgánica del Tribunal Supremo de Justicia.

- Ley de Asignaciones Económicas Especiales Derivadas de Minas e Hidrocarburos.

- Ley Especial de Liquidación del Fondo Intergubernamental para la Descentralización (FIDES).

- Ley de Reforma Parcial de la Ley de Tierras y Desarrollo Agrario.

- Ley de la Actividad Aseguradora.

- Ley de Supresión y Liquidación del Instituto Autónomo Corporación Venezolana Agraria (CVA).

- Ley sobre la Condecoración Orden Libertadores y Libertadoras de Venezuela.

- Ley de Mercado de Valores. 
- Ley de Reforma Parcial del Decreto n 5330, con Rango, Valor y Fuerza de Ley Orgánica de Reorganización del Sector Eléctrico.

- Ley de Reforma Parcial del Código de Ética del Juez Venezolano y Jueza Venezolana.

- Ley de Reforma Parcial de la Ley de Contrataciones Públicas.

- Ley Orgánica de Drogas.

- Ley de la Bolsa Pública de Valores Bicentenaria.

- Ley de Reforma Parcial de la Ley de Cajas de Ahorro, Fondos de Ahorro y Asociaciones de Ahorro Similares.

- Ley de Reforma Parcial de la Ley de Timbre Fiscal.

- Ley de Reforma Parcial de Conscripción y Alistamiento Militar.

- Ley Especial de Timbre Fiscal para Timbre Fiscal para el Distrito Capital.

- Ley sobre Procedimientos Especiales en Materia de Protección Familiar de Niños, Niñas y Adolescentes.

- Ley Orgánica del Sistema y Servicio Eléctrico.

- Ley de Reforma de la Ley Orgánica de Ciencia, Tecnología e Innovación.

- Ley que autoriza al Presidente de la República para Dictar Decretos con Rango, Valor y Fuerza de Ley en las materias que se delegan.

- Ley Orgánica de Contraloría Social.

- Ley Orgánica de las Comunas.

- Ley Orgánica del Poder Popular.

- Ley Orgánica del Sistema Económico Comunal.

- Ley Orgánica de Planificación Pública y Popular.

- Ley de Reforma Parcial de la Ley de Responsabilidad Social en Radio y Televisión.

- Ley de Reforma Parcial de la Ley de Partidos Políticos, Reuniones Públicas y Manifestaciones.

- Ley de Reforma Parcial de la Ley Orgánica de la Contraloría General de la República y del Sistema Nacional de Control Fiscal.

- Ley de Defensa de la Soberanía Política y Autodeterminación Nacional.

- Ley de Regularización de los Períodos Constitucionales y Legales de los Poderes Públicos Estadales Municipales.

- Ley de Reforma Parcial de la Ley Orgánica del Poder Público Municipal.

- Ley de Reforma de la Ley Orgánica de Telecomunicaciones.

- Decreto N 7936, con Rango, Valor y Fuerza de Ley Orgánica de Creación del Fondo Simón Bolívar para la Reconstrucción.

- Ley del Cuerpo de Bomberos y Bomberas y Administración de Emergencia de Carácter Civil del Distrito Capital.

- Ley de Reforma Parcial de la Ley de los Consejos Estadales de Planificación Pública.

- Ley de Gestión Integral de la Basura.

- Ley de Reforma Parcial de los Consejos Locales de Planificación Pública. 
Leyes sancionadas por la Asamblea Nacional en 2011
Leyes sancionadas mediante decreto presidencial en $2011^{14}$
- Ley especial de endeudamiento complementaria para el ejercicio fiscal 2011.

- Ley Orgánica del Deporte, Actividad Física y Educación Física.

- Ley Orgánica contra la discriminación racial.

- Ley de Condecoraciones del Distrito Capital.

- Ley para sancionar los crímenes, desapariciones, torturas y otras violaciones de los derechos humanos por razones políticas en el período 1958-1998.

- Ley sobre donación y trasplante de órganos, tejidos y células en seres humanos.

- Ley para la regulación de la Ley de ejercicio de la medicina.

- Ley de uso racional y eficiente de la energía.

- Ley de regulación y control del sistema de ventas programadas.

- Ley contra la estafa inmobiliaria.

- Ley de presupuesto para el ejercicio fiscal 2012.

- Ley especial de endeudamiento anual para el ejercicio fiscal 2012.

- Ley de Reforma de la Ley penal del ambiente.

- Ley sobre el régimen, administración y aprovechamiento de minerales no metálicos del Distrito Capital.

- Ley Orgánica de la Jurisdicción Especial de Justicia de Paz Comunal.

- Ley Orgánica de Emolumentos, Pensiones y Jubilaciones de los Altos Funcionarios del Poder Público.
- Reforma de la Ley orgánica que reserva al Estado las actividades de Exploración y Explotación del Oro.

- Ley para la Gran Misión en Amor Mayor Venezuela.

- Ley para la Gran Misión Hijos de Venezuela.

- Ley que autoriza la creación de fondos en las instituciones bancarias del sector público para el financiamiento de la adquisición y reparación de viviendas en condición de arrendamiento.

- Ley de creación del territorio Insular Francisco de Miranda.

- Ley Orgánica de Dependencias Federales.

- Ley orgánica que reserva al Estado las actividades de Exploración y Explotación del Oro.

- Reforma parcial de la Ley Orgánica de la Administración Financiera del Sector Público.

- Ley de Costos y Precios Justos.

- Ley del Banco Agrícola de Venezuela.

- Ley de Tasas Portuarias.

- Ley para la Transformación y Reconstrucción Integral de la Región de Barlovento, estado Miranda.

- Ley de Supresión y Liquidación del Fondo para el Desarrollo Endógeno.

- Reforma Parcial de la Ley Orgánica del Trabajo.

- Ley que crea Contribución Especial por Precios Extraordinarios y precios exorbitantes en el Mercado Internacional de Hidrocarburos.

\section{Democracia liberal versus radical: La expansión del poder comunal}

Política e institucionalmente hablando, Venezuela aún tiene estructuras representativas con su origen en un modelo liberal de democracia, incluso en sus procesos electorales. No obstante, desde varios años se han desarrollado experimentos con otros modelos democráticos en Venezuela y otros países del continente, caracterizados por la ambición de animar a la participación popular y la inclusión de los sectores sociales que anteriormente estaban marginalizados. A partir de 2010, el modelo chavista de democracia participativa se ha expandido, incluso con nuevas leyes -como se pudo observar en el capítulo anterior-

14 Además, por decreto presidencial también se dictó una cantidad de leyes aprobatorias de cooperación agrícola, comercial, marítima, etcétera, con otras naciones, así como otras leyes por decreto. Datos tomados de la página web de la Asamblea Nacional (2010-2011): http:/ / www.asambleanacional.gob.ve 
para incentivar y expandir la participación popular a nivel local, lo que se presentará más adelante en el estudio.

Desde 2006 las unidades organizativas principales de democracia participativa local en Venezuela son los Consejos Comunales, una continuación de los Consejos Locales de Planificación Pública/CLPP que fueron establecidos ya en 2002 (a través del artículo 182 de la Constitución de 1999 y la ley de los CLPP de 2002). Los Consejos de Planificación experimentaron dificultades en su trabajo de prioridades laborales al nivel comunal y frecuentemente fueron cooptados por los alcaldes municipales. El artículo 184 de la Constitución instituyó los mecanismos y la jurisdicción para la participación popular y el autogobierno comunal y vecinal, pero los alcaldes así como los gobernadores regionales aún tenían la posibilidad de intervenir y controlar. La Ley de Consejos Comunales de 2006 fue lanzada para corregir este defecto, y dio a los líderes comunales autosuficiencia en su relación con políticos de otras instituciones locales. Chávez y otros críticos argüían además que las alcaldías y las gobernaciones mostraban ineficiencia o incluso ignorancia hacia necesidades a nivel vecinal y por eso la ley de los consejos comunales fue necesaria.

Los Consejos Comunales están autorizados para administrar y desarrollar proyectos sociales locales y de organizar actividades dentro de su jurisdicción territorial. Hay más de 30.000 consejos comunales en Venezuela. Según cifras oficiales de 2010, este año fueron aprobados y refundados 21.050 consejos comunales (en Goldfrank, 2012: 44). En comparación con los Círculos Bolivarianos -la forma organizativa principal de las bases del chavismo entre los años 2000 y 2004- los consejos comunales son organizaciones más grandes. Cada consejo está constituido por entre 200 y 400 familias a nivel urbano y se organiza en diferentes comités temáticos. En las zonas rurales a partir de 20 familias pueden organizarse en un Consejo Comunal y en las comunidades indígenas el mínimo es de diez familias. Según el artículo 2 de la Ley de Consejos Comunales (2006):

Los Consejos Comunales en el marco constitucional de la democracia participativa y protagónica, son instancias de participación, articulación e integración entre las diversas organizaciones comunitarias, grupos sociales y los ciudadanos y ciudadanas, que permiten al pueblo organizado ejercer directamente la gestión de las políticas públicas y proyectos orientados a responder a las necesidades y aspiraciones de las comunidades en la construcción de una sociedad de equidad y justicia social. ${ }^{15}$

Sin embargo, la estructura de los consejos frecuentemente ha presentado una autonomía débil. Igualmente han dependido altamente de fondos económicos del gobierno a nivel nacional, particularmente del Ministerio de Participación y Protección Social y otras instituciones del Estado. Pero asimismo pueden solicitar apoyo económico de las autoridades políticas locales y regionales. Los consejos deben presentar una propuesta de proyecto para luego posiblemente tener su aprobación y financiamiento (Ellner, 2009: 12), lo que fácilmente podría contribuir a una acentuación de clientelismo y paternalismo selectivo del Estado. Este es uno de los retos más difíciles de los Consejos Comunales. En muchos casos, las relaciones entre el Estado nacional y los Consejos Comunales 
se han caracterizado más por sus rasgos de clientelismo y paternalismo que por un fortalecimiento más genuino y autónomo de la participación popular. Hay, igualmente, casos de malversación de fondos y oportunismo por parte de los dirigentes comunales. Existen otros casos, no obstante, en los cuales sí hay una participación popular más autónoma, democrática y transparente. Asimismo, la participación popular y el autogobierno -así como la descentralización política en general- son procesos de concientización, de aprendizaje. Como una cantidad de académicos liberales, la economista Christi Rangel (2010: 87) prefiere el mantenimiento del sistema anterior de autoridades descentralizadas, en particular de las alcaldías. Rangel ve con ansiedad la desconexión entre los consejos comunales y los gobiernos municipales, lo que según ella debería interpretarse como un signo de declive democrático. Benjamin Goldfrank (2012) por su parte no ve evidencias claras de que los avances de los consejos comunales amenazarían y debilitarían a las instituciones representativas y liberales.

Ahora bien, en uno de los primeros estudios analíticos de los consejos comunales el sociólogo Edgardo Lander (2007) concluyó que los desafíos centrales se encontrarán dentro del Estado y en las tensiones entre dinámicas políticas y estructuras institucionales. Por un lado, el Estado es el promotor tras este proceso democrático, pero por otro lado el mismo Estado constituye un freno para la autonomía de las organizaciones populares. El Estado es por consiguiente tanto el acelerador de las políticas de participación popular y el obstáculo potencial para el desarrollo del mismo proceso.

Es necesario destacar, sin embargo, que la insistencia en la lucha vecinal sugiere que hay un impacto en la mentalidad de los ciudadanos, en la percepción de las posibilidades de influir en las decisiones políticas a nivel local. Por cierto, la gran mayoría de estos activistas fueron directamente animados para involucrarse en las políticas organizativas locales por el presidente Chávez. Igualmente, Steve Ellner enfatiza que hasta la fecha, en la práctica el trabajo de los consejos comunales está lejos de una situación de remplazar a las autoridades municipales, ya que principalmente laboran proyectos de prioridad en su vecindad. Ellner también resalta que las organizaciones comunales deben examinarse en su perspectiva histórica:

La fijación en la autonomía absoluta, sin embargo, puede ser exagerada. Los programas sociales y las organizaciones que ellos crean -y no los movimientos sociales autónomosrepresentan la columna vertebral del movimiento chavista. Antes de la elección de Chávez en 1998, Venezuela carecía de la clase de movimientos sociales vibrantes bien organizados que prepararon el camino para la elección de Evo Morales en Bolivia y Rafael Correa en Ecuador. Durante muchos años en Venezuela, los movimientos de vecinos y de cooperativas de trabajadores eran independientes del Estado, pero no prosperaron ni jugaron un papel fundamental en las vidas de los venezolanos no privilegiados. Por contraste, la inyección del gobierno de Chávez de grandes sumas de dinero en los consejos comunales y otros programas sociales ha servido para estimular a los sectores marginales y mostrarles formas de tomar control de sus vidas. Específicamente, recursos del Estado tales como asignaciones a los proyectos de los consejos comunales, préstamos a las cooperativas de trabajadores y becas para estudiantes inscritos en programas educacionales especiales (conocidos como 
"misiones") han sido esenciales en activar a la población en forma organizada. A pesar de la dependencia financiera del Estado, los chavistas de la base que participan en estos programas tienden a ser críticos y su apoyo al gobierno es lejos de ser incondicional. Así se explica, por ejemplo, la derrota de Chávez en el referéndum constitucional de 2007 (Ellner, 2009: 13-14).

Debe subrayarse -reconectando al comentario de Ellner sobre la posición crítica de muchos integrantes de los Consejos Comunales- que hay una creciente cantidad de activistas de la oposición política que han entrado las estructuras políticas comunales, es decir, reconociendo este espacio participativo al nivel local. Rosa Reyes, vocera principal de un Consejo Comunal en San Agustín, Caracas, opina que los avances de los Consejos Comunales han cambiado la vida de los vecinos, al mismo tiempo reconoce algunos desafíos en cuanto al proceso participativo:

Lo interesante de este proceso de los Consejos Comunales, lo novedoso es que es la participación de toda la comunidad, independientemente de las aspiraciones políticas. Hay gente que no milita en ningún partido, hay gente que milita en partidos opositores, y la gente nuestra que simpatiza con el proceso revolucionario. Hay gente de la oposición que reconoce -aunque muy poquita- pero que reconoce por lo menos que este es un logro de la revolución (Reyes, entrevista, 2011).

No obstante, dentro del mismo esquema hay un segmento de representantes vecinales que se sienten excluidos desde las preferencias político-partidistas. En 2011 se formó un "Frente de Consejos Comunales Excluidos", dirigido por el parlamentario opositor William Ojeda, quien expresa la siguiente posición:

El Estado no puede estar al servicio de una parcialidad ni ser apéndice del partido de gobierno, sino que es una infraestructura que debe estar al servicio de todos los ciudadanos por igual... El Poder popular o es plural, o no es poder y menos popular, será una entelequia deslegitimada por una práctica discriminatoria que no se la cala Venezuela (Frente de Consejos Comunales Excluidos, 2011).

Para enfatizar el valor estratégico de las organizaciones comunales en Venezuela, para la nueva estructura del Estado (del Poder Popular), el vicepresidente de Venezuela, Elías Jaua, clarifica que esta preferencia -incluso de invertir más recursos económicos directamente al nivel comunal- se debe a la visión de reimpulsar "a las comunidades organizadas como núcleo de la descentralización bolivariana y del poder popular" (El Nacional, 20 de abril, 2011) ${ }^{16}$ Ampliamente hablando, se pueden identificar cuatro categorías de consejos comunales con respecto a su composición e identificación político-partidista:

1) Chavismo más "leal" (incondicional?)

2) Oficialismo crítico (más autónomo)

3) Consejos mixtos (con opositores y oficialistas constructivos)

4) Consejos Comunales Excluidos (Lalander, 2012). ${ }^{17}$

Artículo: "Consejos comunales recibieron Bs 147 millones más que las alcaldías".

Sobre todo de la oposición política actual, pero igualmente hay consejos comunales que se identifican con el chavismo que han expresado sentimientos de exclusión (observaciones y entrevistas personales en Venezuela, junio de 2011). 
Desde la perspectiva democratizadora, la segunda y tercera de las categorías son evidentemente las más interesantes, ya que se trata de los esfuerzos de trabajo en conjunto para mejorar las condiciones de vida en la vecindad e identificar y resolver los problemas que puedan tener en común, más allá de los clivajes político-partidistas. Democracia tiene sus raíces en conflictos sociales, distintos intereses y prioridades entre los ciudadanos. El consenso y los compromisos entre las diferentes voluntades constituyen el pulso en este demos vecinal. Por ende, se resalta la importancia de pluralismo y debate constructivo dentro de los consejos. La primera categoría -el chavismo más "leal"- por supuesto podría ser democratizadora también, mientras que haya pensamiento crítico y debate democrático interno. Respecto a la cuarta categoría -los consejos comunales excluidos- es por cierto un reto fundamental para este modelo de democracia local comunitaria desarrollar el sistema institucional y financiero para que no se percibiera como "sólo para los fieles" (chavistas), es decir, eliminar definitivamente cualquier práctica de paternalismo selectivo. En todos los sistemas democráticos siempre existen riesgos de evaluación arbitraria en cuanto a la aprobación financiera desde arriba de proyectos solicitados desde abajo, así que para su perfeccionamiento los consejos comunales dependen no sólo de los esfuerzos de los integrantes de la estructura comunal, sino también de la actitud de gobernantes a nivel local, regional y nacional.

En cuanto a la participación dentro de los Consejos Comunales, la mayoría de los dirigentes (voceros/voceras) son mujeres, lo que agrega una dimensión cualitativa adicional desde el ángulo de los argumentos de democratización-inclusión en el establecimiento y desarrollo de estas organizaciones de base, es decir, un empoderamiento de actores que anteriormente estaban excluidos desde los clivajes de género. Frecuentemente se expresa en Venezuela que "La Revolución tiene cara de mujer". La vocera Rosa Reyes confirma esta dimensión de la transformación participativa:

Antes la participación era baja, muy poca, y la mayoría de los que participaban eran los hombres, en lo político y lo social... Ahora la participación es masiva y la mayoría de los que participamos somos las mujeres. ¿Por qué lo digo? Porque en las reuniones de los comités de tierra la mayoría eran mujeres. En las reuniones de los consejos comunales, la mayoría; muchas mujeres. Por eso es que decimos que ahora el proceso es más participativo y de las mujeres. Nuestro presidente dice que es un feminista y que "la revolución tiene cara de mujer". Las mujeres andamos participando en todos los procesos, en los Consejos Comunales, en los movimientos de mujeres, en todo lo que es la formación en la universidad bolivariana, en la misión cultura, en todo lo que es el movimiento de participación nosotras estamos insertas allí (Reyes, entrevista, 2011).

La politóloga Sujatha Fernandes arguye que en general las mujeres de los sectores marginalizados se han fortalecido en cuanto a su participación política, más allá de los consejos comunales, en otros programas y misiones sociales de Estado. No obstante, Fernandes también destaca que el culto a Chávez tiende a estar fuertemente presente entre las mujeres organizadas (Fernandes, 2007). 
Desde 2010, la democracia participativa venezolana se ha expandido. Como se pudo observar en la tabla anteriormente de nuevas leyes, el año 2010 vio modificaciones legales del sistema de descentralización y la participación popular, entre otros a través de las siguientes nuevas leyes:

- La Ley Orgánica de las Comunas

- (Nueva) Ley Orgánica del Consejo Federal de Gobierno

- Ley Orgánica del Poder Popular

- Ley Orgánica de Contraloría Social

- Ley Orgánica de Planificación Pública y Popular

- Ley Orgánica del Sistema Económico Comunal

Asimismo es importante aclarar que debe haber una dinámica entre las nuevas leyes, el esqueleto jurídico -la Constitución de la República- y el Proyecto Nacional Simón Bolívar con sus Lineas Generales del Plan de Desarrollo Económico y Social de la Nación, 20072013, que explícitamente es un plan socialista de desarrollo.

La Ley de Comunas significa la posibilidad para un grupo de Consejos Comunales para construir una Comuna. Por su parte, las Comunas pueden unirse para formar una Ciudad Comunal, una evolución que más claramente podría desafiar la autoridad de las alcaldías. Por un lado podría crearse confusión acerca de la jurisdicción entre la ciudad comunal y la alcaldía, pero por otro lado una estructura participativa igualmente podría completar a la otra instancia -la autoridad política representativa- y el éxito de tal sistema de poderes paralelos depende de la capacitación y concientización de los actores, tanto los vecinos y voceros de los Consejos Comunales, las Comunas y las Ciudades Comunales como los alcaldes, gobernadores, concejales municipales, y gerentes y funcionarios en otras instituciones del Estado.

No obstante, hay diferentes interpretaciones y visiones dentro del oficialismo sobre cómo debe desarrollarse el modelo comunitario. En octubre de 2010 emergió un conflicto interno dentro del chavismo. Hay segmentos dentro del chavismo que preferirían desmantelar las alcaldías y gobernaciones. El diputado nacional y dirigente del PSUV Aristóbulo Istúriz expresó que era necesario:

"desmontar las alcaldías y gobernaciones... es un paso indispensable para el avance efectivo del proceso de cambios socialistas en Venezuela... Con estas alcaldías, con estas gobernaciones no vamos a hacer la revolución, cuyo avance depende de que de alguna manera se vaya "desmontando la estructura del sistema" de democracia representativa para sustituirlo por otro donde el pueblo sea el protagonista" (El Universal, 17 de octubre, 2010). ${ }^{18}$

Por su parte, antes de eso el presidente Chávez había declarado lo siguiente al respecto: "¿A quién se le puede ocurrir que nosotros vamos a acabar con las alcaldías (...), las gobernaciones?... por el contrario, el proceso socialista... desde 1999 requiere 
que esas figuras político-administrativas sean de verdad sólidas y democráticas"

(El Universal, 17 de octubre, 2010).

Es importante enfatizar que el modelo de democracia participativa a través de los Consejos Comunales de hecho constituye el caso más notorio en participación popular e inclusión social en toda América Latina, considerando que casi la tercera parte de la población adulta participa en estos proyectos. Benjamín Goldfrank compara el desarrollo del modelo comunitario en Venezuela con otros proyectos en América Latina, como en Porto Alegre, Brasil, donde sólo unos porcientos de la población participaron (Goldfrank, 2012: 47).

\section{¿CRISIS EN EL CHAVISMO?}

¿Se puede hablar de una crisis dentro del chavismo, o por lo menos un debilitamiento relativo, incluso antes de la oficialización de la enfermedad de Chávez en junio del 2011? Creo que sí, y por diferentes razones. La tendencia electoral indica hacia un debilitamiento en apoyo: entre 1998 y 2006 el oficialismo obtuvo alrededor de $60 \%$ en los comicios y referéndums populares, pero posteriormente su apoyo popular ha disminuido a 50\% aproximadamente, por ejemplo en el referéndum constitucional de 2007 y las elecciones parlamentarias de 2010. Otro ejemplo: cuando se creó el Partido Socialista Unido de Venezuela / PSUV en 2006-2007, la ambición era la de formar el partido político más democrático y representativo de la historia venezolana. Hasta la fecha no ha alcanzado sus metas, si bien es cierto que en número de votos es el partido más fuerte de Venezuela. No obstante, el PSUV aún no está fuertemente institucionalizado, y una debilidad del partido se encuentra en la presencia activa de prominentes ministros y gobernadores oficialistas en la directiva partidista, lo que afecta negativamente la necesaria independencia en su función de supervisar la labor del Estado (Ellner, 2011: 435).

Asimismo el PSUV -y el movimiento chavista más ampliamente hablando- se caracteriza por un faccionalismo marcado entre los "optimistas culturales" y la facción "realista". Los optimistas culturales -entre los cuales se incluye al Presidente- trabajan bajo la bandera de justicia social y fomentan las ideas de cooperativismo, democracia comunitaria a través de Consejos Comunales sin fines de lucro. Los realistas, por su parte, enfatizan la necesidad de supervisar la eficiencia institucional del Estado y controlar rigurosamente el manejo de fondos de cooperativas, Consejos Comunales y otras organizaciones de base (Ellner, 2010).

Considerando el descontento social asociado a los colapsos temporales de los sistemas de electricidad y agua, así como la constante crítica incluso entre las bases chavistas de la mala administración gubernamental, puede interpretarse como sorprendente que el oficialismo aún cuenta con alrededor del $50 \%$ de apoyo según los procesos electorales (p.ej. Wilpert, 2010). Durante mis visitas recientes al país -en 2007, 2009 y 2011-pude constatar que entre las bases vecinales chavistas generalmente hay una confianza sólida en el máximo líder, es decir en Chávez, pero frecuentemente se muestran más escépticos hacia las estructuras representativas del chavismo y se critica la ineficiencia 
y la burocracia institucional, el oportunismo, clientelismo, corrupción y mentalidad individualista capitalista de algunos parlamentarios, líderes subnacionales e incluso dirigentes comunales. El flagelo de la corrupción equivalentemente sigue presente en los venezolanos como una de las preocupaciones principales y expresiones críticas acerca del estado de la democracia, como en todas las democracias latinoamericanas (Latinobarómetro, 2011). ${ }^{19}$ Ya al ser electo el 6 de diciembre de 1998 Chávez declaró que iba a ser implacable con la corrupción, sin embargo, indudablemente sigue siendo uno de los problemas y debilidades principales del gobierno. Luego, el Presidente ha admitido repetidamente que los azotes y desafíos principales de su administración tratan precisamente de la corrupción, la burocracia y la ineficiencia institucional.

\section{LA ENFERMEDAD DEL PRESIDENTE Y LA PRECAMPAÑA ELECTORAL 2012}

Ahora bien, ya en mayo de 2011 hubo señales del debilitamiento físico del Presidente que incluso tuvo que suspender una gira oficial a Brasil, Cuba y Ecuador. Luego el 5 de junio salió de Venezuela y durante el resto del mes Hugo Chávez se mantuvo incomunicable. Ya a su salida de Venezuela circulaban rumores sobre la enfermedad del Presidente, pero nadie podía decir con certeza. Luego, durante la continuación del mes de junio emergieron cantidades de rumores, especulaciones, incluso falsas informaciones sobre la supuesta muerte del primer mandatario. No se sabía con certeza ni siquiera en qué país se encontraba. Altos funcionarios del gobierno dieron abstractas explicaciones del estado de Chávez durante el período. Se organizaron misas, rituales indígenas y otros eventos para rezar por la mejora de Chávez, como pude observar durante mi visita al país el mismo mes de junio. La enfermedad del Presidente causó severa preocupación en las bases del chavismo, especialmente considerando la incertidumbre acerca de la disposición de Chávez de participar con fuerza en las elecciones presidenciales del 2012. Finalmente, el 30 de junio el Presidente se comunicó con Venezuela desde Cuba y dio la explicación de su ausencia, una operación de células cancerígenas. Pocos días después regresó a Venezuela, y su estilo discursivo también se había suavizado luego de la enfermedad, cambiando el eslogan de "Patria, socialismo o muerte" por "Viviremos y venceremos", por lo menos durante los primeros meses desde junio.

Ya durante mi trabajo de campo en Venezuela a mediados del 2011 pude constatar que los actores políticos principales, tanto de la oposición como del oficialismo, se concentraban en sus estrategias y preocupaciones relacionadas a las elecciones del 2012. El estado de salud del Presidente es igualmente utilizado como estrategia electoral. Con frecuencia el presidente Chávez hace paralelos entre su lucha (y supuesta victoria) contra el cáncer y la batalla política contra los opositores..$^{20}$

Según el reporte de Transparencia Internacional de 2011, Venezuela se presenta como uno de los peores países de Latinoamérica en términos de corrupción. Citado en El Universal, 2 de diciembre, 2011, ver también: http://www.transparencia.org.ve

20 No obstante, luego en febrero de 2012 el Presidente admitió que se había detectado otra lesión cancerígena. 
La enfermedad de Chávez no es el único golpe físico al chavismo. Asimismo, varios dirigentes chavistas importantes fallecieron durante el bienio. Ya se mencionó el accidente fatal del gobernador y ex presidente de la Asamblea Nacional Willian Lara. Otros dirigentes importantes que murieron son Francisco Mieres (profesor revolucionario), Luis Villafañe (intelectual y jefe político), el asambleísta Luis Tascón, el General Alberto Müller Rojas, el comunista, autor y editor Guillermo García Ponce y la dirigente radical Lina Ron. Durante la estadía del presidente Chávez en Cuba en junio del 2011, asimismo falleció el Contralor General de la República Clodosbaldo Russián Uzcátegui. Curiosamente, en este contexto algunos venezolanos supersticiosos arguyen que existe una "Maldición del Panteón de Bolívar". Hugo Chávez había ordenado -el 16 de julio del 2010- que se abriera en su presencia el sarcófago donde estaban los restos del Libertador latinoamericano Simón Bolívar, y por ende se explicarían los fallecimientos de los dirigentes mencionados y el cáncer del Presidente por este mito como un castigo por no haberle dejado descansar en paz al Libertador.

Reconectando al proceso de precampaña electoral, del mismo modo los políticos y precandidatos de la oposición iniciaron la movilización electoral en el 2011. La estrategia de alianza aplicada en las elecciones parlamentarias de 2011 se mantiene bajo la MUD (Mesa de Unidad Democrática) y el proyecto de un Gobierno de Unidad Nacional. Los precandidatos por la Unidad eran: Pablo Pérez, gobernador del estado Zulia, apoyado, entre otros, por los partidos Nuevo Tiempo, Acción Democrática, COPEI y Convergencia; María Corina Machado, asambleísta y políticamente independiente, y Henrique Capriles Radonski, gobernador del estado Miranda, apoyado por los partidos Primero Justicia, Causa R, Podemos y Patria Para Todos/PPT. Inicialmente, también figuró como precandidato Leopoldo López, ex alcalde del municipio Chacao en Caracas, lanzado por los partidos Voluntad Popular y Proyecto Venezuela, entre otros, pero luego decidió unirse a la candidatura de Capriles Radonski, quien se destacó como el más fuerte según los sondeos de opinión. ${ }^{21}$

El presidente Chávez, por su parte, rechaza los comentarios de que estaría en campaña electoral en 2011, y sugiere que simplemente está gobernando para el pueblo, más que todo en relación a las misiones del Estado. Como fue mencionado, cuatro misiones se han lanzado en 2011, de estas, Agro Venezuela y la Gran Misión Vivienda estaban marchando ya antes de la enfermedad de Chávez. Mediante decreto legislativo presidencial, Chávez sancionó la ley para la Gran Misión Hijos de Venezuela el 12 de diciembre de 2011, y el día siguiente fue ejecutada la ley que estableció la Gran Misión en Amor Mayor Venezuela. La Misión Hijos de Venezuela aporta una ayuda financiera a las madres en circunstancias de pobreza, principalmente las adolescentes, o con hijos con alguna discapacidad. Sólo luego de un mes de funcionamiento, esta misión había registrado 594.821 familias en

21 Capriles ganó las primarias en febrero de 2012 con el 62\% de las preferencias. Es interesante observar que ganó el candidato menos agresivo en cuanto a la crítica del régimen chavista, y que incluso reconoció algunos avances del chavismo en lo político y social. Asimismo participó en las primarias un candidato del sindicalismo y la vieja izquierda, Pablo Medina, ex líder de los partidos Causa R y PPT que en la actualidad representa el Movimiento Laborista. Finalmente, se registró la candidatura de Diego Arria, diplomático y economista con una trayectoria política desde los años 60 y un perfil más conservador. 
necesidad (Correo del Orinoco, 20 de enero, 2012). ${ }^{22}$ La Misión Amor Mayor Venezuela tiene el objetivo de proteger y apoyar económicamente -a través de pensiones- a las mujeres mayores de 55 años y hombres mayores de 60, principalmente a los que viven en situaciones de ingresos inferiores al salario mínimo. Al presentarse la Misión Hijos de Venezuela, pude observar por la televisión estatal venezolana cómo el Presidente incluso entregó una vivienda a una madre adolescente (VTV, 12 de diciembre de 2011), lo que por supuesto por un lado podría ser una expresión de la preocupación social de Hugo Chávez, pero al mismo tiempo refleja el peligro del paternalismo estatal y el populismo, lo que sin lugar a dudas podría contribuir al debilitamiento de la credibilidad del Estado.

\section{REFLEXIONES FINALES}

Los años 2010 y 2011 en Venezuela presentan avances sociales, controversias políticas, así como asombros e incertidumbres en cuanto al futuro político del país. En 2010, el regreso de la oposición a la Asamblea Nacional -con más del 50\% de los votos- confirma la tendencia de un aumento de respaldo electoral a la oposición, mientras que el oficialismo se ha debilitado en términos de apoyo electoral a contar de 2006. A partir de junio del 2011 el debate se ha concentrado más que todo en la enfermedad del Presidente y los escenarios para el 2012 y las elecciones presidenciales. En este artículo se presentó un resumen político de Venezuela durante el bienio y asimismo se ha resaltado algunos avances sociales, como las misiones y la reducción de la pobreza, así como algunos retos y debilidades actuales en el sistema político venezolano. Las políticas estatales de las misiones pueden interpretarse tanto como progresistas en sus ambiciones de llevar a cabo una más profunda transformación de las estructuras sociales, pero al mismo tiempo tienen su componente asistencialista/paternalista. La concentración de poder en el Presidente es evidentemente todavía un problema de la democracia venezolana, si bien es cierto que al mismo tiempo hay una profundización de la democracia con los avances de los Consejos Comunales y otras organizaciones de base. El destino del proceso democrático radical y participativo dependerá de la continua capacitación y concientización democrática de los actores involucrados en estos procesos, y también de la salud del presidente Chávez y del resultado de las elecciones presidenciales del 2012.

\section{REFERENCIAS ${ }^{23}$}

Asamblea Nacional de la República Bolivariana de Venezuela (varios años), www.asambleanacional.gob.ve CEPAL (2011), Balance preliminar de las economías de América Latina y el Caribe 2011, datos sobre Venezuela accesibles en: http://www.eclac.cl/publicaciones/xml/1/45581/2011-881_BPE_Venezuela_29dic11.pdf

CNE/ Consejo Nacional Electoral (2010), http:/ / www.cne.gov.ve

Correo del Orinoco (2011-2012), http:/ / www.correodelorinoco.gob.ve/

Ellner, Steve (2011), “Venezuela's Social Based Democratic Model: Innovations and Limitations”, en: Journal of Latin American Studies, Vol. 43: 421-449.

23. Todas las fuentes de internet revisadas entre diciembre 2011 y marzo 2012. 
Ellner, Steve (2010), “The Perennial Debate over Socialist Goals Played Out in Venezuela”, en: Science E Society, Vol. 74. Accesible también en: http://venezuelanalysis.com/analysis/5290

Ellner, Steve (2009), "A New Model with Rough Edges: Venezuela's Community Councils", en: NACLA. Report on the Americas, May/June 2009.

El Nacional (varios años), http:/ / www.el-nacional.com

El Universal (varios años), http:/ / www.eluniversal.com

Fernandes, Sujatha (2007), "Barrio Women and Popular Politics in Chávez's Venezuela", en: Latin American Politics \& Society, Vol. 49, No. 3: 97-127.

Frente de Consejos Comunales Excluidos (2011), http:/ / consejoscomunalesexcluidos.blogspot.com/2011/03/ creado-frente-de-consejos-comunales.html

Goldfrank, Benjamin (2011), “Los Consejos Comunales: ¿avance o retroceso para la democracia venezolana?, en: Íconos. Revista de Ciencias Sociales, núm. 40: 41-55. FLACSO, Quito.

Lalander, Rickard (2012), "Neo-Constitutionalism in Twenty-First Century Venezuela: Participatory Democracy, Deconcentrated Decentralization or Centralized Populism?", en: Detlef Nolte \& Almut Schilling-Vacaflor (editors) New Constitutionalism in Latin America: Promises and Practices, Ashgate Publishing Limited, Farnham, Surrey (en prensa).

Lander, Edgardo (2007), "El Estado y las tensiones de la participación popular en Venezuela". In: OSAL, Año VIII, No 22, CLACSO, Buenos Aires.

Latinobarómetro (2010-2011), http:/ / www.latinobarometro.org

López-Maya, Margarita (2011), "Venezuela entre incertidumbres y sorpresas", en: Nueva Sociedad, No. 235.

Ministerio del Poder Popular para la Comunicación y la Información (2009), Proyecto Nacional Simón Bolivar: Lineas Generales del Plan de Desarrollo Económico y Social de la Nación, 2007-2013, República Bolivariana de Venezuela, Caracas.

O'Donnell, Guillermo (1994), "Delegative Democracy", en: Journal of Democracy, Vol. 5, No. 1.

Rangel, Christi (2010), "Municipios, consejos comunales y democracia en Venezuela", en: Revista Procesos históricos, No. 17, Universidad de los Andes, Mérida.

República Bolivariana de Venezuela (2006), Ley de los Consejos Comunales. Reglamento orgánico del servicio autónomo Fondo Nacional de los Consejos Comunales, Gaceta Oficial No 5.806 Extraordinario del 10 de abril de 2006, Caracas.

RNV/Radio Nacional de Venezuela (2012), http:/ / www.rnv.gob.ve/

Súmate (2010), Análisis parlamentarias 2010, accesible en: http://www.sumate.org/Especiales/ Parlamentarias/AnalisisSumateParlamentarias2010.pdf

Transparencia Venezuela, http:/ /www.transparencia.org.ve

Venezuelanalysis.com (varios años), http://venezuelanalysis.com

VTV (Venezolana de Televisión), http://www.vtv.gob.ve

Wilpert, Gregory (2010), "A New Opportunity for venezuela's Socialists", en: Venezuelanalysis.com, 1 octubre, 2010, http://venezuelanalysis.com/print/5683

\section{Entrevistas (selección)}

Reyes, Rosa, Caracas, 9 de junio, 2011.

Rickard Lalander. Politólogo, Doctor y Catedrático en Estudios Latinoamericanos, Universidad de Helsinki, Finlandia, investigador y profesor en el Instituto de Estudios Latinoamericanos, Universidad de Estocolmo, Suecia, y el Departamento de las Culturas del Mundo, Universidad de Helsinki. Es investigador asociado de la Universidad Andina Simón Bolívar, Quito. En Venezuela ha colaborado como investigador y profesor, entre otras, en la Universidad del Zulia, Maracaibo, Universidad de los Andes, Mérida, Universidad Central de Venezuela y la Universidad Simón Bolívar, ambas en Caracas. Es autor de Retorno de los Runakuna. Cotacachi y Otavalo (2010), Suicide of the Elephants? Venezuelan Decentralization between Partyarchy and Chavismo (2004), editor y coautor de Politica y Sociedad en la Venezuela del Chavismo (2006) y ha publicado ampliamente sobre la democracia en los países andinos. E-mail: rickard.lalander@lai.su.se 
